\title{
Capim-braquiária diferido e adubado com nitrogênio: produção e características da forragem
}

\section{Manoel Eduardo Rozalino Santos ${ }^{1}$, Dilermando Miranda da Fonseca², Eric Márcio Balbino ${ }^{3}$, João Paulo Ismério dos Santos Monnerat ${ }^{1}$, Simone Pedro da Silva ${ }^{1}$}

\author{
${ }_{1}^{1}$ Pós-graduação em Zootecnia - Universidade Federal de Viçosa. Bolsista do CNPq. \\ 2 Departamento de Zootecnia - Universidade Federal de Viçosa. \\ 3 Pós-graduação em Zootecnia - Universidade Federal de Viçosa. Bolsista da FAPEMIG.
}

RESUMO - Este trabalho foi conduzido com o objetivo de avaliar a massa de forragem e de seus componentes morfológicos, a altura e o índice de tombamento do pasto, a densidade volumétrica e o valor nutritivo da forragem em pastos de Brachiaria decumbens cv. Basilisk diferidos e adubados com nitrogênio (N). Avaliaram-se três períodos de diferimento (73, 95 e 116 dias) e quatro doses de nitrogênio $(0,40,80$ e $120 \mathrm{~kg} / \mathrm{ha})$ em um delineamento experimental de blocos casualizados, com três repetições, segundo o esquema de parcelas subdivididas. As massas de forragem total, forragem verde e de colmo verde, bem como a altura do pasto e a densidade volumétrica da forragem aumentaram com o período de diferimento e a dose de nitrogênio. Pastos diferidos por maior período apresentaram maior massa de forragem morta e índice de tombamento. O percentual de fibra em detergente neutro elevou e o teor proteína bruta (PB) diminuiu com o aumento do período de diferimento. O teor de PB aumentou com a elevação da dose de nitrogênio. O período de diferimento e a adubação nitrogenada afetam a produção e as características da forragem diferida de forma semelhante, entretanto o período de diferimento da pastagem possui efeito de maior magnitude. A realização da adubação nitrogenada permite diminuir o período de diferimento do pasto, sem reduzir a produção de forragem.

Palavras-chave: Brachiaria decumbens, densidade volumétrica de forragem, índice de tombamento, massa de forragem, período de diferimento, valor nutritivo

\section{Deferred and fertilized signalgrass: forage production and characteristics}

\begin{abstract}
This research was carried out aiming to assess the forage mass and its morphological components, pasture height and falling index, bulk density and the forage nutritional value on nitrogen $(\mathrm{N})$ fertilized and deferred Brachiaria decumbens cv. Basilisk pastures. The treatments had 73, 95 and 116-day deferring periods, and 0, 40, 80 and $120 \mathrm{~kg} / \mathrm{ha} \mathrm{N}$ doses. A randomized block design with three replicates and subdivided plots was used. Total forage, green forage and green stem mass, as well as pasture height and forage bulk density increased along with the deferring periods and $\mathrm{N}$ doses. The pasture deferred for the longest period showed the highest dead forage mass and falling index. The neutral detergent fiber was high and crude protein (CP) percentage diminished as the deferred period increased. The CP percentage increased as the $\mathrm{N}$ dose increased. The deferring period and the nitrogen fertilization equally affected both deferred forage production and characteristics; however the deferred period has a higher magnitude. Performing nitrogen fertilization allows a reduction in the deferring period of pasture without reducing the forage production.
\end{abstract}

Key Words: Brachiaria decumbens, deferring period, falling index, forage bulk density, forage mass, nutritional value

\section{Introdução}

O diferimento da pastagem é uma estratégia de manejo de fácil realização, baixo custo e que garante estoque de forragem durante o período de sua escassez. Geralmente, a utilização do pasto diferido ocorre na época do ano de maior escassez de forragem em uma região e, assim, o início do diferimento determinará a duração do período de cresci- mento do pasto. Este período de diferimento deve ser fundamentado na rebrotação das plantas forrageiras, que é afetada por fatores climáticos e de manejo.

O período de diferimento determina a idade do pasto no momento de sua utilização e influencia a produção, a composição morfológica e o valor nutritivo da forragem. No Brasil, vários trabalhos foram desenvolvidos objetivando estabelecer as épocas do ano mais apropriadas para realizar 
o diferimento da pastagem e sua utilização (Santos \& Bernardi, 2005). Nestes trabalhos, foram considerados o tipo de forrageira e a região do país para a recomendação do adequado período de diferimento da pastagem.

A adubação nitrogenada também pode permitir maior flexibilização do período de diferimento da pastagem, uma vez que o nitrogênio aumenta a taxa de crescimento da gramínea e, conseqüentemente, a quantidade de forragem produzida por unidade de tempo. Dessa forma, é possível obter produção de forragem semelhante, mesmo adotando-se distintos períodos de diferimento. Diferenças na dose de nitrogênio aplicada no diferimento seriam responsáveis por essa produção semelhante de forragem.

Contudo, a fertilização nitrogenada, quando realizada tardiamente no verão ou outono, quando a umidade do solo começa a reduzir, pode resultar em perdas de nitrogênio por volatilização, dependendo da fonte de nitrogênio utilizada (Martha Jr. et al., 2004). E é justamente no fim do verão e/ou início do outono que geralmente se realiza o início do diferimento das pastagens. Caso essas perdas aconteçam, o resultado esperado da adubação pode ser reduzido, ou até mesmo não ocorrer, resultando em baixa eficiência e recuperação aparente do nitrogênio aplicado e menor produção de forragem.

Este trabalho foi conduzido com o objetivo de avaliar a produção e o valor nutritivo da forragem e algumas características estruturais do pasto de capim-braquiária sob três períodos de diferimento e quatro doses de nitrogênio.

\section{Material e Métodos}

O experimento foi realizado no Setor Forragicultura do Departamento de Zootecnia da Universidade Federal de Viçosa (UFV), em Viçosa, Minas Gerais (2045' S ; 42 $51^{\circ}$ ' W; $651 \mathrm{~m}$ ). Uma área de pastagem de Brachiaria decumbens cv. Basilisk (Stapt.) foi utilizada de janeiro a julho de 2006. O solo da área experimental é um Latossolo VermelhoAmarelo, de textura argilosa e com relevo medianamente ondulado. No início do experimento, realizou-se a amostragem de solo, na camada $0-20 \mathrm{~cm}$, cujos resultados da análise química foram: $\mathrm{pH}$ em $\mathrm{H}_{2} \mathrm{O}: 5,4 ; \mathrm{P}: 1,5$ (Mehlich-1) e K: $115 \mathrm{mg} / \mathrm{dm}^{3} ; \mathrm{Ca}^{+2}: 1,8 ; \mathrm{Mg}^{+2}: 0,7 \mathrm{e} \mathrm{Al}^{+3}: 0,2 \mathrm{cmol}_{\mathrm{c}} / \mathrm{dm}^{3}$ ( $\mathrm{KCl} 1 \mathrm{~mol} / \mathrm{L})$. Durante o período de avaliação, foram monitorados os dados climáticos na área experimental (Tabela 1).

Foram estudadas as combinações entre períodos de diferimento da pastagem, casualizados às parcelas, e doses de nitrogênio $(\mathrm{N})$, casualizadas às subparcelas. Os períodos de diferimento avaliados foram 73, 95 e 116 dias, e as doses de nitrogênio foram $0,40,80$ e $120 \mathrm{~kg} / \mathrm{ha}$. Foi adotado o delineamento em blocos casualizados, em esquema de parcelas subdivididas, com três repetições. Cada parcela media $12,375 \mathrm{~m}^{2} \mathrm{e}$, descontando-se a área de bordadura, possuía área útil de $5,25 \mathrm{~m}^{2}$.

Antes da implantação dos tratamentos, a altura do pasto foi monitorada semanalmente e mantida em de $20 \mathrm{~cm}$. No dia 6 de fevereiro de 2006, aplicaram-se $50 \mathrm{~kg} / \mathrm{ha}$ de $\mathrm{P}_{2} \mathrm{O}_{5}$, na forma de superfosfato simples, em toda área experimental.

As datas de início do diferimento ocorreram em 7/3/2006, 28/3/2006 e 19/4/2006, quando o nitrogênio foi aplicado em dose única, na forma de uréia e ao final da tarde. Em seguida, as parcelas foram irrigadas a fim de elevar a umidade do solo e reduzir as possíveis perdas de nitrogênio por volatilização. Todas as parcelas permaneceram diferidas até o dia 1/7/2006, data considerada apropriada para o início do período de utilização das pastagens diferidas na região de Viçosa. Nesta data, também foram avaliadas todas variáveis respostas.

Primeiramente, foram medidas as alturas do pasto e da planta estendida em cinco pontos por parcela. A altura do pasto em cada ponto foi determinada utilizando-se o instrumento descrito por Fagundes (2004) e teve como critério a distância entre a parte da planta localizada mais alto no dossel e o nível do solo. A altura da planta estendida foi mensurada estendendo-se os perfilhos da gramínea no sentido vertical e anotando-se a maior distância do nível do solo até o ápice dos perfilhos. A criação do índice de tombamento das plantas teve como finalidade determinar, de forma menos subjetiva, o grau de acamamento constatado

Tabela 1 - Médias mensais da temperatura média diária, insolação, precipitação pluvial total mensal e evaporação total mensal durante os períodos de janeiro a julho de 2006

\begin{tabular}{lcccc}
\hline Mês & Temperatura média do ar $\left({ }^{\circ} \mathrm{C}\right)$ & Insolação (horas/dia) & Precipitação pluvial (mm) & Evaporação $(\mathrm{mm})$ \\
\hline Janeiro & 23,1 & 7,2 & 180,0 & 108,6 \\
Fevereiro & 23,6 & 9,4 & 84,8 & 82,4 \\
Março & 22,6 & 5,6 & 186,5 & 62,5 \\
Abril & 20,7 & 5,3 & 56,0 & 56,8 \\
Maio & 17,2 & 5,3 & 6,4 & 59,4 \\
Junho & 16,1 & 5,1 & 21,0 & 64,4 \\
Julho & 15,7 & 6,5 & 6,3 & 79,0 \\
\hline
\end{tabular}


em alguns pastos diferidos e foi calculado pelo quociente entre a altura da planta estendida e a altura do pasto.

Para determinação da massa de forragem e de seus componentes morfológicos, foi realizado o corte, no nível do solo, de todos os perfilhos contidos no interior de um quadrado de $0,25 \mathrm{~m}^{2}$ em duas áreas representativas da condição média do pasto em cada parcela. As amostras foram acondicionadas em saco plástico e, no laboratório, foram pesadas. De cada amostra, foram retiradas duas subamostras: uma delas foi pesada, acondicionada em saco de papel e colocada em estufa com ventilação forçada, a $65^{\circ} \mathrm{C}$, durante 72 horas; e a outra foi separada, manualmente, em lâmina foliar verde (LV), colmo verde (CV) e forragem morta (FM). A inflorescência e a bainha foliar verdes foram incorporadas à fração colmos verdes. A parte da lâmina foliar que não apresentava sinais de senescência (órgão de cor verde) foi incorporada à fração lâminas foliares verdes. As partes do colmo e da lâmina foliar senescentes e mortos (com amarelecimento e/ou necrosamento do órgão) foram incorporadas à fração forragem morta. Após a separação, os componentes foram pesados e secos em estufa de circulação forçada de ar a $65^{\circ} \mathrm{C}$, por 72 horas.

A densidade volumétrica da forragem e de seus componentes morfológicos, expressa em $\mathrm{kg} / \mathrm{cm}$.ha, foi calculada pela divisão da massa de forragem e da massa de seus componentes morfológicos pela altura do pasto, respectivamente.

Nas amostras de forragem total, determinaram-se os teores de matéria seca (MS), fibra em detergente neutro (FDN) e compostos nitrogenados totais (PB), de acordo com as técnicas descritas por Silva \& Queiroz (2002). A FDN indigestível (FDNi) foi estimada considerando a digestibilidade in situ, por 240 horas no rúmem de vacas fistuladas da raça Holandesa. A matéria seca potencialmente digestível (MSpoD) foi calculada de acordo com Paulino et al. (2006).
Para cada característica, foi realizada análise de variância e, posteriormente, análise de regressão, cujo maior modelo de superfície de resposta às médias das combinações de períodos de diferimento e doses de nitrogênio foi o seguinte:

$$
Y_{i}=\beta_{0}+\beta_{1} D_{i}+\beta_{2} N_{i}+\beta_{3} D_{i} N_{i}+e_{i}
$$

em que: $Y_{i}=$ variável-resposta; $D_{i}=$ período de diferimento; $\mathrm{N}_{\mathrm{i}}=$ dose de nitrogênio; $\beta_{0}, \beta_{1}, \beta_{2}, \beta_{3}=$ parâmetros a ser estimados; $\mathrm{e}_{\mathrm{i}}=$ erro experimental.

O grau de ajustamento dos modelos foi avaliado pelo coeficiente de determinação e pela significância dos coeficientes de regressão, testada pelo teste t corrigido com base nos resíduos da análise de variância. Foram calculados os coeficientes de variação referentes à parcela $(\mathrm{CV}$ a) e à subparcela ( $\mathrm{CV}$ b) para cada variável-resposta. Todas as análises estatísticas foram realizadas no nível de significância de até $10 \%$ de probabilidade, usando o Sistema para Análises Estatísticas - SAEG, versão 8.1 (UFV, 2003).

\section{Resultados e Discussão}

As massas de forragem total e dos seus componentes morfológicos aumentaram de forma linear com o aumento do período de diferimento e das doses de nitrogênio (Tabela 2).

A massa de lâmina foliar verde (LV) aumentou $(\mathrm{P}<0,01)$ com a aplicação de nitrogênio. Possivelmente, dois fatores explicam esse resultado: o nitrogênio pode ter aumentado a duração de vida da folha (DVF) e o número de folhas (NF) de perfilhos individuais (Garcez Neto et al., 2002). Esta justificativa é controversa, pois a duração de vida da folha parece ser apenas ligeiramente afetada pela disponibilidade de nitrogênio e, freqüentemente, o que se observa é o aumento nas taxas de senescência foliar em condições de alta disponibilidade deste nutriente (Nascimento Jr. \& Adese, 2004). Todavia, os perfilhos nos pastos diferidos de capim-braquiária desenvolveram, predominantemente, durante o outono e inverno (períodos de diferimento).

Tabela 2 - Estimativas das massas de lâmina foliar verde, colmo verde, forragem verde, forragem morta e forragem total em pastos de capimbraquiária sob três períodos de diferimento (D) e quatro doses de nitrogênio (N)

\begin{tabular}{|c|c|c|c|c|}
\hline Massa (kg/ha) & Equação & $\mathrm{r}^{2}(\%)$ & $\mathrm{CV} \mathrm{a}^{1}(\%)$ & $\mathrm{CV} \mathrm{b}^{2}(\%)$ \\
\hline Lâmina foliar verde & $\hat{\mathrm{Y}}=915,65+9,28708 * * \mathrm{~N}$ & 0,88 & 23,85 & 18,52 \\
\hline Colmo verde & $\hat{\mathrm{Y}}=-2483,65+42,314 * \mathrm{D}+17,8411 * \mathrm{~N}$ & 0,98 & 38,74 & 24,53 \\
\hline Forragem verde & $\hat{\mathrm{Y}}=-1561,61+42,241^{+} \mathrm{D}+27,133 * * \mathrm{~N}$ & 0,98 & 32,38 & 20,79 \\
\hline Forragem morta & $\hat{\mathrm{Y}}=-654,31+30,284 * \mathrm{D}$ & 0,69 & 27,50 & 32,46 \\
\hline Forragem total & $\hat{Y}=-2316,53+70,771 * D+31,154 * * N$ & 0,95 & 27,11 & 22,93 \\
\hline
\end{tabular}

${ }^{1}$ Coeficiente de variação referente ao fator período de diferimento; ${ }^{2}$ Coeficiente de variação referente ao fator dose de nitrogênio; ** Significativo pelo teste $\mathrm{t}(\mathrm{P}<0,01)$;

* Significativo pelo teste $\mathrm{t}(\mathrm{P}<0,05){ }^{+}$Significativo pelo teste $\mathrm{t}(\mathrm{P}<0,10)$. 
Nestas épocas, as temperaturas são mais baixas e podem resultar em maior duração de vida das folhas.

A inexistência de efeito $(\mathrm{P}>0,10)$ do período de diferimento na massa de lâminas foliares verdes pode ser atribuída à compensação entre massa de forragem total e percentual de lâminas foliares verdes. Pastos diferidos por maior período apresentaram, em média, mais massa de forragem total $(7.665 \mathrm{~kg} / \mathrm{ha}$ de $\mathrm{MS})$, porém com menor percentual de lâminas foliares verdes (20,33\%). Comportamento contrário foi constatado nos pastos submetidos a menor período de diferimento $(4.844 \mathrm{~kg} / \mathrm{ha}$ de forragem total, com 30,05\% de LV, em média).

A maior $(\mathrm{P}<0,05)$ massa de colmo verde com o aumento da dose de nitrogênio (Tabela 2) pode ser explicada pelo aumento no número de perfilhos por unidade de área e, principalmente, pelo maior peso dos perfilhos nesses pastos. Perfilhos mais pesados possuem colmo mais desenvolvido, como forma de garantir a sustentação das folhas. De fato, o diâmetro das estruturas de suporte (colmo) altera-se em proporção direta à força requerida para suportar seus órgãos (folhas) e não isometricamente com o seu peso (McMahom, 1973). O período de diferimento também contribuiu para o aumento da massa de colmos verdes. Inicialmente, durante os períodos de diferimento, ocorreu aumento do índice de área foliar (IAF) do pasto, resultando em maior competição por luz entre os perfilhos. Nessa condição, a planta prioriza a alocação de carbono no alongamento dos entrenós para posicionar a nova área foliar nas camadas menos sombreadas do dossel (Lemaire, 2001).

A massa de forragem morta $(\mathrm{FM})$ aumentou $(\mathrm{P}<0,05)$ nos pastos sob maior período de diferimento (Tabela 2). Nesses pastos, a maior competição por luz resulta no sombreamento das folhas mais baixas e na morte de perfilhos menores (Lemaire, 2001), o que acentua a senescência e a participação de material morto na forragem diferida. Maior massa de forragem morta no pasto diferido prejudica o valor nutritivo da forragem e a estrutura do pasto, fatores determinantes do consumo e desempenho animal.

Como a massa de forragem verde (FV) é constituída pelo somatório das massas de lâminas foliares e colmos verdes, é natural o seu aumento com os maiores períodos de diferimento $(\mathrm{P}<0,10)$ e doses de nitrogênio $(\mathrm{P}<0,01)$ (Tabela 2). Ressalta-se que colmos verdes $(60,8 \%)$ são em média o maior constituinte da massa de forragem verde, comparativamente à massa de lâminas foliares verdes $(39,2 \%)$. O aumento da massa de forragem total $(\mathrm{P}<0,05)$ com a dose de nitrogênio se deve ao aumento da massa de forragem verde nessas condições, uma vez que o nitrogênio não afetou $(\mathrm{P}>0,10)$ a massa de forragem morta $(\mathrm{FM})$. O aumento $(\mathrm{P}<0,05)$ da massa de forragem total em pastos diferidos por maior período deveu-se às maiores massas de forragem verde e forragem morta nestes pastos (Tabela 2).

$\mathrm{O}$ aumento das massas de forragem verde e forragem total com os maiores níveis dos fatores estudados permite recomendar ao produtor a adubação nitrogenada como forma de flexibilizar a duração do período de diferimento da pastagem. Assim, semelhante massa de forragem pode ser obtida com períodos de diferimento distintos, se ocorrerem variações na dose de nitrogênio aplicada no início do período de diferimento da pastagem. Neste trabalho, o pasto diferido por maior período (116 dias) e sem adubação nitrogenada produziu semelhante massa de forragem (4.979 kg/ha) em comparação àquele diferido por menor período ( 73 dias) e adubado com $80 \mathrm{~kg} /$ ha de nitrogênio, que produziu $4.901 \mathrm{~kg} / \mathrm{ha}$ de matéria seca. Ressalta-se, porém, que existe a possibilidade de ocorrer grandes perdas de nitrogênio por volatilização quando fontes de adubo nitrogenado, com uréia, são utilizadas em épocas do ano em que o solo encontra-se com menor umidade (Martha Jr. et al., 2004). Neste caso, o efeito esperado do nitrogênio pode não ocorrer e redução do período de diferimento pode resultar em menor produção de forragem diferida. Nesse sentido, a utilização de fontes de adubo nitrogenado menos susceptíveis à volatilização, como o sulfato de amônio e o nitrato de amônio (Martha Jr. et al., 2004), é uma forma de reduzir a perda de nitrogênio por volatilização.

Em pastagens diferidas, é comum constatar a formação de uma estrutura de pasto peculiar, caracterizada pelo posicionamento dos perfilhos no sentido horizontal. Isso ocorre principalmente nas pastagens diferidas por maior período, que possuem maiores massas de forragem total e forragem morta. Uma das consequências dessa estrutura de pasto é o possível aumento das perdas de forragem durante o pastejo e a menor eficiência de utilização da forragem produzida. Com o intuito de caracterizar a ocorrência dessa estrutura em pastos diferidos, foi utilizada a metodologia proposta por Santos (2007) para mensurar o índice de tombamento em pastos diferidos.

A altura do pasto e a da planta estendida aumentaram nas pastagens submetidas ao maior período de diferimento $(\mathrm{P}<0,01)$ e adubadas com maior dose de nitrogênio $(\mathrm{P}<0,01)$ (Tabela 3). O maior período de diferimento resulta no prolongamento da competição por luz no dossel. E a maior dose de nitrogênio intensifica a competição. Como uma das respostas à competição por luz é a elevação da taxa de alongamento do colmo, os perfilhos tornam-se maiores (maior peso e comprimento) e os pastos e as plantas apresentam maior altura. 
Tabela 3 - Estimativas da altura do pasto, da planta estendida e do índice de tombamento em pastagens de capim-braquiária sob três períodos de diferimento (D) e quatro doses de nitrogênio $(\mathrm{N})$

\begin{tabular}{lcccc}
\hline Característica & Equação & $\mathrm{r}^{2}(\%)$ & $\mathrm{CV} \mathrm{a}^{1}(\%)$ & $\mathrm{CV} \mathrm{b}(\%)$ \\
\hline Altura do pasto $(\mathrm{cm})$ & $\hat{\mathrm{Y}}=-24,30+0,6519 * * \mathrm{D}+0,1668^{*} * \mathrm{~N}$ & 0,82 & 11,11 & 10,44 \\
Altura da planta estendida $(\mathrm{cm})$ & $\hat{\mathrm{Y}}=-57,48+1,0666^{* *} \mathrm{D}+0,1955^{* * \mathrm{~N}}$ & 0,96 & 20,55 & 17,70 \\
Índice de tombamento & $\hat{\mathrm{Y}}=0,4796+0,007132 * \mathrm{D}$ & 0,62 & 12,86 & 19,23 \\
\hline
\end{tabular}

${ }^{1}$ Coeficiente de variação referente ao fator período de diferimento; ${ }^{2}$ Coeficiente de variação referente ao fator dose de nitrogênio; $* *$ Significativo pelo teste $\mathrm{t}(\mathrm{P}<0,01)$;

* Significativo pelo teste $\mathrm{t}(\mathrm{P}<0,05)$.

O índice de tombamento (IT) aumentou $(\mathrm{P}<0,05)$ apenas com o período de diferimento do pasto (Tabela 3). Pastos diferidos por maior período apresentaram plantas mais compridas (maior APE), que não se mantiveram eretas em condições de campo. O colmo do capim-braquiária é delgado e flexível, o que, por um lado, predispõe o uso desta forrageira como pasto diferido, mas predispõe as plantas ao tombamento. É importante realçar que, mesmo com baixo índice de tombamento, alguns pastos diferidos de capimbraquiária possuíam alto potencial de acamamento. Esse fato foi confirmado principalmente nos pastos de maior altura. A ocorrência de tombamento dos perfilhos em pastos diferidos pode ser reduzida com a adoção de reduzido período de diferimento ou com a aplicação de menor dose de nitrogênio na data de diferimento da pastagem.

$\mathrm{O}$ acamamento de um pasto diferido resulta no aumento da densidade volumétrica da forragem, já que mesma quantidade de massa de forragem por unidade de área passa a ocupar menor altura do pasto. Essa alteração na densidade volumétrica da forragem, em conjunto com a sua composição morfológica, determina mudanças estruturais no pasto que interferem no comportamento ingestivo animal (Gomide $\&$ Gomide, 2001).

As densidades da forragem e dos seus componentes morfológicos foram afetadas pelo período de diferimento e pela adubação nitrogenada (Tabela 4). Maior período de diferimento da pastagem aumentou as densidades de colmos verdes $(\mathrm{P}<0,05)$, forragem verde $(\mathrm{P}<0,10)$, forragem morta $(\mathrm{P}<0,05)$ e forragem total $(\mathrm{P}<0,05)$. Além disso, o aumento nas doses de nitrogênio também causou $(\mathrm{P}<0,05)$ aumento nas densidades de lâminas foliares verdes, colmo verde, forragem verde e forragem total. Todos esses resultados foram determinados pelo aumento na massa de forragem e dos seus componentes morfológicos (Tabela 2).

$\mathrm{O}$ valor médio de densidade volumétrica de lâminas foliares verdes em pastos diferidos foi igual a $25,48 \mathrm{~kg} / \mathrm{cm}$.ha. As densidades volumétricas médias de colmo verde $(43,40 \mathrm{~kg} / \mathrm{cm}$.ha) e de forrragem morta $(36,16 \mathrm{~kg} / \mathrm{cm}$.ha) foram elevadas nestes pastos. Estas características estruturais poderiam limitar o consumo dos animais, uma vez que o consumo máximo ocorre quando os animais estão em pastagens com alta densidade de folhas acessíveis (Euclides et al.,1999) e o colmo constitui-se barreira à desfolhação, reduzindo a facilidade de colheita da forragem pelo animal em pastejo (Carvalho et al., 2005).

O pasto diferido é resultado de uma condição particular de manejo da pastagem, que determina suas características específicas, como maiores massas de material morto e de colmo. Assim, maiores densidades desses componentes morfológicos no pasto diferido já eram esperadas, o que faz com que a importância destas características seja contextualizada. Além disso, os bovinos consumem os colmos verdes em pastos diferidos de Brachiaria decumbens, portanto, este componente morfológico não

Tabela 4 - Estimativas das densidades volumétricas de lâmina foliar verde (LV), colmo verde (CV), forragem verde (FV), forragem morta (FM) e forragem total (FT) em pastagens de capim-braquiária sob três períodos de diferimento (D) e quatro doses de nitrogênio $(\mathrm{N})$

\begin{tabular}{lcccc}
\hline Densidade $(\mathrm{kg} / \mathrm{cm} . \mathrm{ha})$ & Equação & $\mathrm{r}^{2}(\%)$ & $\mathrm{CV} \mathrm{a}^{1}(\%)$ & $\mathrm{CV} \mathrm{b}^{2}(\%)$ \\
\hline Lâmina foliar verde & $\hat{\mathrm{Y}}=15,57+0,1579 * * \mathrm{~N}$ & 88,43 & 23,85 & 18,52 \\
Colmo verde & $\hat{\mathrm{Y}}=-42,24+0,7196^{*} \mathrm{D}+0,3034 * * \mathrm{~N}$ & 97,58 & 38,74 & 24,53 \\
Forragem verde & $\hat{\mathrm{Y}}=-26,56+0,718^{+} \mathrm{D}+0,4615^{* * \mathrm{~N}}$ & 97,83 & 32,38 & 20,79 \\
Forragem morta & $\hat{\mathrm{Y}}=-11,123+0,5150 * \mathrm{D}$ & 68,50 & 27,50 & 32,46 \\
Forragem total & $\hat{\mathrm{Y}}=-34,54+1,1139 * \mathrm{D}+0,5687 * * \mathrm{~N}$ & 93,99 & 27,59 & 22,93 \\
\hline
\end{tabular}

${ }^{1}$ Coeficiente de variação referente ao fator período de diferimento; ${ }^{2}$ Coeficiente de variação referente ao fator dose de nitrogênio; ** Significativo pelo teste $\mathrm{t}(\mathrm{P}<0,01)$; * Significativo pelo teste $\mathrm{t}(\mathrm{P}<0,05) ;{ }^{+}$Significativo pelo teste $\mathrm{t}(\mathrm{P}<0,10)$. 
Tabela 5 - Estimativa da composição bromatológica da forragem em pastagens diferidas de capim-braquiária sob três períodos de diferimento (D) e quatro doses de nitrogênio $(\mathrm{N})$

\begin{tabular}{|c|c|c|c|c|}
\hline Característica & Equação & $\mathrm{r}^{2}(\%)$ & $\mathrm{CV} \mathrm{a}^{1}(\%)$ & $\mathrm{CV} \mathrm{b}^{2}(\%)$ \\
\hline Proteína bruta & $\hat{\mathrm{Y}}=7,99-0,04592 * * \mathrm{D}+0,009254 * * \mathrm{~N}$ & 0,90 & 14,06 & 8,66 \\
\hline Fibra em detergente neutro (FDN) & $\hat{\mathrm{Y}}=63,14+0,1244 * \mathrm{D}$ & 0,57 & 3,84 & 2,66 \\
\hline FDN indigestível & $\bar{Y}=29,5495$ & - & 13,66 & 14,33 \\
\hline MSpoD & $\bar{Y}=69,95$ & - & 5,71 & 6,06 \\
\hline
\end{tabular}

MSpoD - matéria seca potencialmente digestível.

${ }^{1}$ Coeficiente de variação referente ao fator período de diferimento; ${ }^{2}$ Coeficiente de variação referente ao fator dose de nitrogênio; ** Significativo pelo teste $\mathrm{t}(\mathrm{P}<0,01)$; * Significativo pelo teste $\mathrm{t}(\mathrm{P}<0,05)$.

seria propriamente uma "barreira" à desfolhação nesta condição (Santos, 2007).

A modificação do valor nutritivo da forragem pelos períodos de diferimento e pelas doses de nitrogênio já era esperada (Tabela 5), pois estes fatores modificaram as características estruturais dos pastos diferidos. Maiores períodos de diferimento causaram diminuição $(\mathrm{P}<0,01)$ no teor de proteína bruta $(\mathrm{PB})$ e aumento $(\mathrm{P}<0,05)$ na concentração de fibra em detergente neutro (FDN) da forragem. Estes resultados podem ser explicados pelo fato de que os pastos diferidos por maior período apresentam maior massa de forragem morta, um constituinte da forragem com pior valor nutritivo. De outra forma, maiores doses de nitrogênio resultaram em incremento $(\mathrm{P}<0,01)$ no teor de $\mathrm{PB}$ na forragem diferida. Possivelmente, a maior disponibilidade de nitrogênio no solo fez com que sua absorção pelas plantas aumentasse, ocasionando maior teor de nitrogênio nos tecidos vegetais. Além disso, pastos diferidos e adubados com maior dose de nitrogênio possuíam maior massa de lâminas foliares verdes, componente morfológico da forragem com maior teor de nitrogênio (Santos, 2007).

$\mathrm{O}$ coeficiente angular do fator dose de nitrogênio para PB da forragem é aproximadamente cinco vezes menor que o do período de diferimento. Isso indica que a adubação nitrogenada tem efeito limitado e pequeno na melhoria do teor de PB da forragem diferida e seu efeito é mais pronunciado sobre o aumento da produção de forragem (Tabela 2). Dessa forma, a determinação do adequado período de diferimento da pastagem constitui estratégia de manejo mais efetiva para melhorar o valor nutritivo da forragem diferida.

O teor de PB da forragem diferida variou de 2,86 a 5,97\% e manteve-se abaixo do limite inferior de $7 \%$, proposto por Van Soest (1994) como necessário para manter as exigências nutricionais dos microrganismos ruminais.

A amplitude de variação dos teores de FDN foi de 70,99 a $80,81 \%$, que podem ser considerados valores elevados e tenderiam a limitar o consumo animal. Realmente, de acordo com Van Soest (1994), a FDN é o constituinte do alimento rotineiramente medido que mais consistentemente se relaciona à ingestão, porque está associada à ocupação de espaço no rúmem e possui menor taxa de desaparecimento no trato digestivo.

Os teores de fibra em detergente neutro indigestível (FDNi) e matéria seca potencialmente digestível (MSpoD) não foram influenciados pelos períodos de diferimento. Possivelmente, os valores dessas características foram fortemente afetados pelo menor período de diferimento da pastagem avaliado, o que explicaria a ausência de efeitos dos fatores estudados. O elevado teor médio de FDNi $(29,6 \%)$ nas forragens confirma que o pasto diferido, de forma geral, possui baixo valor nutritivo. Nessa condição, uma estratégia de manejo apropriada seria a realização da suplementação do pasto com os nutrientes deficientes na forragem, como forma de aumentar o consumo e o desempenho dos animais mantidos nestas pastagens (Paulino et al., 2006).

O período de diferimento da pastagem causou efeito de maior magnitude sobre as características da forragem diferida e as equações de regressão ajustadas confirmaram esse comportamento. Em todas as equações que continham efeitos dos dois fatores estudados, o coeficiente angular foi sempre superior para o período de diferimento, em comparação ao do fator dose de nitrogênio. Além disso, $87 \%$ das equações ajustadas indicaram efeito significativo para o período de diferimento e $73 \%$, para a dose de nitrogênio. Dessa forma, a adequação do período de diferimento da pastagem constitui ação de manejo prioritária e essencial para conciliar produção de forragem em quantidade e qualidade.

A natureza dos efeitos do período de diferimento e da adubação nitrogenada foi igual para todas as características avaliadas, exceto para o teor de PB da forragem. Do total de equações ajustadas, com efeitos concomitantes do período de diferimento e da dose de nitrogênio, aproximadamente $89 \%$ possuíram igual sinal para os dois coeficientes angulares. 


\section{Conclusões}

O período de diferimento e a adubação nitrogenada aumentam as massas de forragem total, forragem verde e de colmo, a altura e a densidade volumétrica em pastos de capim-braquiária. O período de diferimento aumenta a massa de forragem morta e o índice de tombamento do pasto e reduz o valor nutritivo da forragem de capim-braquiária. $\mathrm{O}$ período de diferimento tem efeito semelhante e de maior magnitude na produção e nas características da forragem em comparação à adubação nitrogenada em pastagens diferidas. A adubação nitrogenada permite a diminuição do período de diferimento do pasto, sem reduzir a sua produção de forragem. Para utilização no início de julho, na região de Viçosa, a pastagem de Brachiaria decumbens cv. Basilisk pode ser diferida por cerca 115 ou 70 dias, concomitantemente à aplicação de $40 \mathrm{ou} 80 \mathrm{~kg} / \mathrm{ha}$ de nitrogênio, respectivamente.

\section{Literatura Citada}

CARVALHO, P.C.F.; GENRO, T.C.M.; GONÇALVES, E.N. et al. Estrutura do pasto como conceito de manejo: reflexos sobre consumo e a produtividade. In: SIMPÓSIO SOBRE VOLUMOSOS NA PRODUÇÃO DE RUMINANTES, 2., 2005, Jaboticabal. Anais... Jaboticabal: FUNEP, 2005. p.107-124.

EUCLIDES, V.P.B.; THIAGO, L.R.S.; MACEDO, M.C.M. Consumo voluntário de forragem de três cultivares de Panicum maximum sob pastejo. Revista Brasileira de Zootecnia, v.28, n.6, p.1177-1185, 1999.

FAGUNDES, J.L. Características morfogênicas e estruturais do pasto de Brachiaria decumbens Stapf. adubado com nitrogênio. 2004. 76f. Tese (Doutorado em Zootecnia) Universidade Federal de Viçosa, Viçosa, MG, 2004.

GARCEZ NETO, A.F.; NASCIMENTO JR, D.; REGAZZI, A.J. et al. Avaliação de características morfogênicas do Panicum
Maximum cv. Mombaça em resposta à adubação nitrogenada e alturas de corte. In: REUNIÃO ANUAL DA SOCIEDADE BRASILEIRA DE ZOOTECNIA, 39., 2002, Recife. Anais... Recife: Sociedade Brasileira de Zootecnia, [2002] (CD-ROM).

GOMIDE, J.A.; GOMIDE, C.A.M. Utilização e manejo de pastagens. In: REUNIÃO ANUAL DA SOCIEDADE BRASILEIRA DE ZOOTECNIA, 38., 2001, Piracicaba. Anais... Piracicaba: Sociedade Brasileira de Zootecnia, 2001. p.808-825.

LEMAIRE, G. Ecophysiology of grasslands: dynamic aspects of forage plant populations in grazed swards. In: INTERNATIONAL GRASSLAND CONGRESS, 19., 2001, São Pedro. Proceedings... São Pedro: Fundação de Estudos Agrários Luiz de Queiroz, 2001. p.29-37.

McMAHOM, C. Size and shape in biology. Science, v.179, p.1201-1204, 1973.

MARTHA JR., G.B.; VILELA, L.; BARIONI, L.G. et al. Manejo da adubação nitrogenada em pastagens. In: SIMPÓSIO SOBRE MANEJO DA PASTAGeM, 21., 2004, Piracicaba. Anais... Piracicaba: Fundação de Estudos Agrários Luiz de Queiroz, 2004. p.155-216.

NASCIMENTO JR., D.; ADESE, B. Acúmulo de biomassa na pastagem. In: SIMPÓSIO SOBRE MANEJO ESTRATÉGICO DA PAStAGEM, 2., 2004, Viçosa, MG. Anais... Viçosa, MG: Universidade Federal de Viçosa, 2004. p.289-330.

PAULINO, M.F.P.; DETMANN, E.; VALADARES FILHO, S.C. Suplementação animal em pasto: energética ou protéica? In: SIMPÓSIO SOBRE MANEJO ESTRATÉGICO DA PASTAGEM, 3., 2006, Viçosa, MG. Anais... Viçosa, MG: Universidade Federal de Viçosa, 2006. p.359-392.

SANTOS, M.E.R. Características da forragem e produção de bovinos em pastagens de capim-braquiária diferidas. 2007. 100f. Dissertação (Mestrado em Zootecnia) Universidade Federal de Viçosa, Viçosa, MG, 2007.

SANTOS, P.M.; BERNARDI, A.C.C. Diferimento do uso de pastagens. In: SIMPÓSIO SOBRE MANEJO DA PASTAGEM, 22., 2005, Piracicaba. Anais... Piracicaba: Fundação de Estudos Agrários Luiz de Queiroz, 2005. p.95-118.

SILVA, D.J.; QUEIROZ, A.C. Análises de alimentos: métodos químicos e biológicos. 3.ed. Viçosa, MG: Universidade Federal de Viçosa, 2002. 235p.

Van SOEST, P.J. Nutritional ecology of the ruminant. 2.ed. Ithaca: Cornell University Press, 1994. 476p.

UNIVERSIDADE FEDERAL DE VIÇOSA - UFV. SAEG - Sistema de análises estatísticas e genéticas. Versão 8.1. Viçosa, MG: 2003. (Apostila). 142p. 